Archives de sciences sociales des religions

176 | octobre-décembre 2016

Bulletin Bibliographique

\title{
Martine Sevegrand, Israël vu par les catholiques (1945-1994)
}

Paris, Éditions Karthala, coll. « Hommes et sociétés », 2014, 264 p.

Olivier Rota

\section{(Q) OpenEdition}

\section{Journals}

Édition électronique

URL : http://journals.openedition.org/assr/28339

DOI : $10.4000 /$ assr.28339

ISSN : $1777-5825$

Éditeur

Éditions de l'EHESS

Édition imprimée

Date de publication : 31 décembre 2016

Pagination : 386

ISSN : 0335-5985

Référence électronique

Olivier Rota, « Martine Sevegrand, Israël vu par les catholiques (1945-1994) », Archives de sciences sociales des religions [En ligne], 176 | octobre-décembre 2016, mis en ligne le 20 juillet 2017, consulté le 24 septembre 2020. URL : http://journals.openedition.org/assr/28339 ; DOI : https://doi.org/10.4000/ assr.28339

Ce document a été généré automatiquement le 24 septembre 2020.

(c) Archives de sciences sociales des religions 


\title{
Martine Sevegrand, Israël vu par les catholiques (1945-1994)
}

Paris, Éditions Karthala, coll. « Hommes et sociétés », 2014, 264 p.

\author{
Olivier Rota
}

\section{RÉFÉRENCE}

Martine Sevegrand, Israël vu par les catholiques (1945-1994), Paris, Éditions Karthala, coll. «Hommes et sociétés », 2014, 264 p.

1 Disons-le d'emblée : la lecture d'Israël vu par les catholiques (1945-1994) nous a laissé un sentiment de malaise. La quatrième de couverture promet « des sources inédites à ce jour ». Or, la plus grande partie de l'ouvrage repose sur des études déjà publiées par d'autres chercheurs. Seule, la seconde partie du volume se révèle originale et constitue une tentative appréciable de retracer le contenu et les orientations des débats français.

2 À première vue, l'ensemble de l'ouvrage donne l'impression d'un travail sérieux. L'auteur a pris le temps de rencontrer des acteurs de l'histoire qu'elle présente. Elle a lu la majorité des ouvrages publiés sur le sujet (mais pas tous les articles, dont certains ont déjà abordé certains aspects présentés dans le livre). Le livre bénéficie d'une belle écriture, fluide et déliée, qui le rend facilement accessible. Il fait le lien entre différentes monographies de chercheurs. Il cite abondamment des articles de presse ou des publications d'époque pas toujours mis en avant, comme le témoignage de Paul Gauthier par exemple.

Or, si l'abondance des citations nous semble une qualité de l'ouvrage, il en est aussi une faiblesse. Les propos rapportés ne sont que rarement critiqués ou placés dans leur contexte. Ce qui conduit à émailler l'ouvrage de citations partiales qui relèvent de l'opinion, et parfois aussi de la falsification. Ainsi, cette dénonciation de "l'annexion unilatérale » de Jérusalem-Est par Israël en 1967 - qui oublie de préciser que cette annexion est une réponse à « l'annexion unilatérale » de cette même partie de la ville par la Jordanie en 1948. Plus gênant: cette citation d'un journaliste qui ne veut pas 
croire que la population arabe a quitté le territoire à l'appel des armées arabes au moment de la première guerre israélo-arabe - alors que le fait est attesté par de nombreux témoins de l'époque. Plus grave: quelques citations sont utilisées à contresens. Une citation de Congar est présentée comme la reconnaissance par le théologien de la «visée universaliste d'Israël » - alors qu'elle vise à démontrer que cette portée universaliste n'est assumée que par l'Église.

4 L'auteur n'est pas spécialiste de la question traitée par l'ouvrage, ce qui la conduit à laisser passer des inexactitudes. La conférence de Seelisberg n'a pas été préparée par le National Council of Christians and Jews américain créé en 1928, mais par le Council of Christians and Jews anglais fondé en 1942. Le Centre catholique d'étude et de documentation sur le judaïsme que Paul Démann souhaitait établir a bien vu le jour : c'est le SIDIC, fondé plus tard par les Sœurs de Sion, que l'auteur mentionne pourtant dans un autre chapitre de l'ouvrage. Le P. Hussar ne militait pas activement « pour une séparation entre les communautés juives et arabes » : il souhaitait plus simplement que soit reconnue la place singulière des catholiques hébréophones dans une Église majoritairement arabe et dont les options théologiques et nationales divergeaient. Si le P. De Vaux, directeur de l'École biblique à Jérusalem-Est, demande que la Maison dominicaine qui se crée en Israël sous le nom de Maison saint-Isaïe n'affiche pas nominalement sa relation à l'ordre des prêcheurs, ce n'est pas parce que le P. Hussar est un " sioniste chrétien » dont on souhaite se démarquer, mais afin de ne pas attirer la suspicion des autorités nationales sur l'École biblique, sise à Jérusalem-Est, dans le contexte d'un climat des plus tendu entre Israël et la Jordanie. Ce n'est qu'après 1967 que les options politiques des deux maisons ont vraiment représenté une pomme de discorde... La liste des inexactitudes est longue... À ces dernières, nous ajouterons notre surprise face à des oublis de taille qui ne se justifient pas par la problématique adoptée (Quid de la campagne violemment antisioniste de Témoignage chrétien, notamment dans les années 1960 ? Quid de son adhésion aveugle à la propagande arabe ?).

5 L'orientation générale de l'ouvrage, nous le regrettons, donne à penser que l'auteur n'est pas parvenue à prendre une distance critique suffisante face au sujet qu'elle découvrait. Les enjeux de la question ne sont pas vraiment saisis. Les nombreuses controverses (théologiques et politiques) entre juifs et chrétiens sont évacuées, ou alors simplifiées. L'auteur tend trop souvent à assimiler l'opinion de tel ou tel catholique publiée dans la presse à une vérité historique. Or, le thème de l'ouvrage supposait justement de mettre en évidence ce que ces opinions ont de construites, partielles, partiales et orientées... ce qui n'a pas été fait de manière systématique.

6 Si l'effort de synthèse est louable et honnête, le résultat est loin d'être complet et satisfaisant. Le volume pourra contenter le lecteur qui s'initie à ce sujet hautement complexe; au prix toutefois d'une information partielle sur un certain nombre de points moins qu'anodins. Paradoxalement peut-être, l'ouvrage pourra intéresser le chercheur averti, capable de passer outre les défauts que nous avons cités, et d'apprécier la somme d'informations réunie ici. 